\title{
Mortality after coronary artery revascularization of patients with rheumatoid arthritis
}

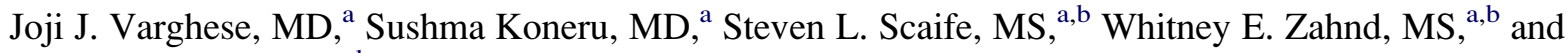 \\ Mark L. Francis, MD ${ }^{\mathrm{a}, \mathrm{b}}$
}

Objective: Patients with rheumatoid arthritis have an increased risk for accelerated arthrosclerosis. It is not known, however, whether this disorder is associated with a higher risk of complications after coronary artery revascularization.

\begin{abstract}
Methods: We conducted a cross-sectional study of patients in the 2003-2005 Nationwide Inpatient Sample. To determine whether patients with rheumatoid arthritis had higher in-hospital mortality after coronary artery revascularization, we used logistic regression to adjust for age, sex, race/ethnicity, income, rural-urban residency, diabetes, hypertension, hyperlipidemia, Charlson comorbidities (including myocardial infarction, congestive heart failure, and diabetes), elective admission, weekend admission, and primary payer.
\end{abstract}

Results: Among patients undergoing coronary artery revascularization, those with rheumatoid arthritis were $49 \%$ less likely to die while hospitalized compared with those without rheumatoid arthritis (odds ratio, 0.51 ; $95 \%$ confidence interval, 0.40-0.65) after adjusting for the above confounders. In subgroup analyses that adjusted for the same confounders, patients with rheumatoid arthritis also had a $61 \%$ improvement of in-patient mortality when they underwent percutaneous coronary interventions (odds ratio, $0.39 ; 95 \%$ confidence interval, $0.29-0.54$ ) along with a median of 0.32 less days hospitalized (95\% confidence interval, $0.28-0.34$ days). Similarly, patients with rheumatoid arthritis undergoing coronary artery bypass grafting had a $31 \%$ improvement of in-patient mortality (odds ratio, $0.69 ; 95 \%$ confidence interval, $0.48-0.99$ ), with a median of 1.36 less days hospitalized (95\% confidence interval, $0.72-1.12$ days).

Conclusion: Among patients undergoing coronary artery revascularization, patients with rheumatoid arthritis have an in-hospital survival advantage along with reduced days of hospitalization compared with patients without rheumatoid arthritis. (J Thorac Cardiovasc Surg 2010;140:91-6)

Patients with rheumatoid arthritis (RA) are predisposed to accelerated atherosclerosis. ${ }^{1}$ Moreover, cardiovascular disease is the leading cause of mortality among patients with RA. ${ }^{2,3}$ Both traditional and nontraditional cardiovascular risk factors contribute to increased atherogenicity in patients with RA. ${ }^{4,5}$ There are, moreover, additional factors that occur more frequently in patients with RA that might contribute to increased mortality, such as increased frequency of diffuse multivessel coronary artery disease, ${ }^{6}$ increased frequency of microvascular coronary artery disease, ${ }^{6}$ systemic inflammation, ${ }^{7}$ and a disparity in the quality of care for coronary artery disease delivered to patients with RA. ${ }^{8}$ Patients with RA are also more likely to have wound-healing problems and infections, including

\footnotetext{
From the Department of Medicine ${ }^{\mathrm{a}}$ and the Division of Rheumatology, ${ }^{\mathrm{b}}$ Southern Illinois University School of Medicine, Springfield, Ill.

Supported by the Department of Medicine at the Southern Illinois University School of Medicine.

Disclosures: None.

Received for publication July 1, 2009; revisions received Aug 25, 2009; accepted for publication Sept 17, 2009; available ahead of print Nov 30, 2009.

Address for reprints: Mark L. Francis, MD, SIU School of Medicine, PO Box 19636, Springfield, IL 62794-9636 (E-mail: mfrancis@siumed.edu). $0022-5223 / \$ 36.00$

Copyright (c) 2010 by The American Association for Thoracic Surgery doi:10.1016/j.jtcvs.2009.09.036
}

sepsis. Some of these same factors could also adversely influence the success of coronary artery revascularization procedures.

Percutaneous coronary interventions (PCIs) and coronary artery bypass grafting (CABG) are the 2 main revascularization strategies for patients with coronary artery disease. The relative frequency and efficacy of these procedures have not been studied in patients with RA. Despite a higher risk for cardiovascular mortality in patients with RA, prior studies have not used RA in models to predict in-hospital mortality in patients undergoing PCI or CABG. ${ }^{9-11}$ Because RA is a risk factor for coronary artery disease, we hypothesized that patients with RA who undergo coronary revascularization procedures would have higher in-hospital mortality compared with that seen in patients without RA. As secondary analyses, we performed subgroup analyses of in-hospital mortality, length of stay, and total hospital charges in patients who underwent either PCI or CABG.

\section{MATERIALS AND METHODS Study Population}

We obtained deidentified data from the Nationwide Inpatient Sample (NIS) through the Agency for Healthcare Research and Quality after institutional review board approval. NIS is a stratified probability sample of state inpatient databases and is the largest all-payer database in the United States. 


$$
\begin{aligned}
& \text { Abbreviations and Acronyms } \\
& \begin{aligned}
\text { CABG } & =\text { coronary artery bypass grafting } \\
\text { CI } & =\text { confidence interval } \\
\text { NIS } & =\text { Nationwide Inpatient Sample } \\
\text { OR } & =\text { odds ratio } \\
\text { PCI } & =\text { percutaneous coronary intervention } \\
\text { RA } & =\text { rheumatoid arthritis }
\end{aligned}
\end{aligned}
$$

For 2003 to 2005, this database contains 23,977,347 discharges from more than 1000 hospitals (approximately $20 \%$ of all hospitals) in 37 states.

\section{Study End Points}

The outcome measure of interest was in-hospital mortality. For secondary analysis, we separately evaluated in-hospital mortality in patients undergoing PCI with and without stent placement and CABG. We also evaluated length of stay and total hospital charges in the PCI and CABG subgroups. The total hospital charges represent cleared charges that do not include professional fees and noncovered charges.

\section{Study Exposure}

For our study population, we selected patients who had undergone coronary artery revascularization with International Classification of Diseases, Ninth Edition, Clinical Modification procedure codes: CABG (36.10-36.19) or PCI (36.01-36.09 and 00.66 for 2005). Among those patients who had undergone coronary artery revascularization, we identified patients with RA by using Clinical Modification codes (7140, 7141, and 7142).

\section{Patient Characteristics}

We determined baseline characteristics that are most likely present at hospital admission for patients with RA. Those patients without RA were considered the control group for our analysis. Baseline characteristics included age, sex, race/ethnicity, quartile income, rural-urban residency, and primary payer for the hospitalization. We used CM codes based on hospital discharge diagnoses to determine the presence of additional known risk factors for atherosclerosis that were available in this database: diabetes, hypertension, and hyperlipidemia. To assess comorbidities, we also used hospital discharge diagnoses to calculate the Deyo modification of the Charlson comorbidity index, ${ }^{12}$ which includes such conditions as acute myocardial infarction, congestive heart failure, peripheral vascular disease, and diabetes. We performed an additional analysis with the Elixhauser comorbidities. ${ }^{13}$ We also assessed whether patients were admitted electively and whether patients were admitted on a weekend or a weekday.

\footnotetext{
Statistical Analysis

Baseline characteristics were analyzed by using either the Fisher's exact test for discrete data or the $t$ test for continuous data. For our analysis of inhospital mortality, we used logistic regression to adjust for baseline characteristics. Our final model included age, age squared, sex, race/ethnicity, quartile income, rural-urban residency, hypertension, hyperlipidemia, Charlson comorbidity index, elective versus nonelective admission, weekend versus weekday admission, and primary payer. Multiple imputations were used for missing data, but the final model was additionally tested among patients including only those who had complete information for all variables. For our analysis of length of stay, we used linear regression on log-transformed length of stay and adjusted for the same confounding variables. Similar log-transformations were used to analyze total hospital charges.
}

Because arthritis is used in the calculation of the Charlson comorbidity index, all patients with RA will have a Charlson index score of at least 1. We therefore did sensitivity analyses to determine whether this factor affected the outcome. For our first sensitivity analysis, we collapsed index scores of 0 and 1 such that all patients had a Charlson comorbidity index of at least 1 . For our second sensitivity analysis, we subtracted 1 from the comorbidity index for patients with RA to remove these factors from the Charlson comorbidity index. For our third sensitivity analysis, we performed a separate analysis with Elixhauser comorbidities with the same secondary adjustments as done for the Charlson comorbidity index.

Statistical analysis was performed with SAS 9.1 (SAS Institute, Inc, Cary, NC) and SUDAAN 9.0 (Research Triangle Institute, Research Triangle Park, NC) software. We used a 2 -sided $P$ value of less than .05 to assess statistical significance for baseline characteristics of the study population and $95 \%$ confidence intervals (CIs) for all other analyses.

\section{RESULTS}

\section{Characteristics of the Study Population}

We identified 680,479 patients who underwent coronary artery revascularization. RA was diagnosed in 5485 $(0.8 \%)$ patients. Among patients who underwent any type of coronary artery revascularization, there were differences in all baseline characteristics between patients with RA and control subjects (Table 1). For instance, patients with RA who underwent coronary artery revascularization were older and more likely white. They were more likely to have hypertension but less likely to have diabetes or hyperlipidemia. They were also more likely admitted on an emergency basis and during weekends.

\section{Multivariable Analysis}

Among patients who underwent coronary artery revascularization, patients with RA were overall equally likely to die while hospitalized compared with patients without RA (Table 2). We then used logistic regression analysis to determine the effect of RA itself on in-hospital mortality after controlling for confounding variables that are associated with RA. In this analysis patients with RA were 49\% less likely to die while hospitalized compared with those in the control group (odds ratio [OR], 0.51; 95\% CI, 0.40-0.65) after adjusting for age, sex, race/ethnicity, quartile income, rural-urban residency, hypertension, hyperlipidemia, Charlson comorbidity index (including myocardial infarction, congestive heart failure, diabetes, and peripheral vascular disease), elective admission, weekend admission, and primary payer (Table 2). This finding is not explained by a single variable; patients with RA had improved survival when each variable was sequentially removed from the model (data not shown). In separate analyses we obtained similar results with the first 2 categories of the Charlson index collapsed, with the elimination of arthritis from the Charlson index for patients with RA, with the use of Elixhauser rather than Charlson comorbidities, and with patients limited to those who had complete information for all variables (data not shown). 
TABLE 1. Characteristics of the study population*

\begin{tabular}{|c|c|c|c|c|c|c|c|c|c|}
\hline \multirow[b]{2}{*}{ Baseline characteristic } & \multicolumn{3}{|c|}{ All revascularized patients } & \multicolumn{3}{|c|}{ Patients receiving only $\mathrm{PCI}$} & \multicolumn{3}{|c|}{ Patients receiving only CABG } \\
\hline & Control group & Rheumatoid arthritis & $P$ value $\dagger$ & Control group & Rheumatoid arthritis & $P$ value $\dagger$ & Control group & Rheumatoid arthritis & $\boldsymbol{P}$ Value $\dagger$ \\
\hline No. $(\%)$ & $674,994(99.2)$ & $5485(0.8)$ & & $483,615(99.2)$ & $3974(0.8)$ & & $185,919(99.2)$ & $1463(0.8)$ & \\
\hline Age, y (SD) & $64.8(12.0)$ & $67.0(10.6)$ & $<.001$ & $64.4(12.3)$ & $66.8(10.9)$ & $<.001$ & $66.0(10.9)$ & $67.5(9.6)$ & $<.001$ \\
\hline Female sex, n (\%) & $219,412(32.5)$ & $2941(53.6)$ & $<.001$ & $163,752(33.9)$ & $2251(56.7)$ & $<.001$ & $54,009(29.0)$ & $669(45.8)$ & $<.001$ \\
\hline Race, n (\%) & & & $<.001$ & & & $<.001$ & & & .004 \\
\hline White & $386,055(81.6)$ & $3265(85.3)$ & & $274,914(81.6)$ & $2320(85.0)$ & & $107,990(81.6)$ & $919(86.0)$ & \\
\hline Black & $30,510(6.4)$ & $250(6.5)$ & & $22,381(6.6)$ & $190(7.0)$ & & $7927(6.0)$ & $58(5.4)$ & \\
\hline Hispanic & $31,690(6.7)$ & $187(4.9)$ & & $22,268(6.6)$ & $134(4.9)$ & & $9135(6.9)$ & $51(4.8)$ & \\
\hline Asian & 8919 (1.9) & $43(1.1)$ & & $5990(1.8)$ & $29(1.1)$ & & $2862(2.2)$ & $14(1.3)$ & \\
\hline Other & $14,946(3.2)$ & $76(2.0)$ & & $10,677(3.2)$ & $51(1.9)$ & & $4148(3.1)$ & $23(2.2)$ & \\
\hline Quartile income, n (\%) & & & $<.001$ & & & .002 & & & .13 \\
\hline $0 \%-25 \%$ & $164,738(25.0)$ & $1266(23.7)$ & & $117,120(24.8)$ & $901(23.2)$ & & $46,267(25.5)$ & 349 (24.6) & \\
\hline $26 \%-50 \%$ & $172,905(26.3)$ & $1538(28.8)$ & & $122,677(26.0)$ & $1101(28.4)$ & & $48,883(27.0)$ & $422(29.7)$ & \\
\hline $51 \%-75 \%$ & $167,261(25.4)$ & 1367 (25.6) & & $120,160(25.5)$ & $1007(26.0)$ & & $45,720(25.2)$ & $353(24.9)$ & \\
\hline $76 \%-100 \%$ & $153,495(23.3)$ & $1178(22.0)$ & & $112,010(23.7)$ & $872(22.5)$ & & $40,267(22.2)$ & $296(20.8)$ & \\
\hline Rural-urban, n (\%) & & & $<.001$ & & & $<.001$ & & & $<.001$ \\
\hline Large metropolitan area & $334,140(49.7)$ & $2463(45.1)$ & & $243,462(50.6)$ & $1833(46.3)$ & & $88,211(47.7)$ & $612(42.0)$ & \\
\hline Small metropolitan area & $201,167(30.0)$ & $1812(33.2)$ & & $141,556(29.4)$ & $1301(32.8)$ & & $57,745(31.2)$ & $492(33.7)$ & \\
\hline Micropolitan area & $77,195(11.5)$ & $656(12.0)$ & & $54,500(11.3)$ & 449 (11.3) & & $22,097(12.0)$ & $200(13.7)$ & \\
\hline Nonurban & $59,232(8.8)$ & $535(9.8)$ & & 41,906 (8.7) & 377 (9.5) & & $16,832(9.1)$ & 154 (10.6) & \\
\hline Hypertension, n (\%) & $433,481(64.2)$ & $3629(66.2)$ & .003 & $306,865(63.4)$ & $2626(66.1)$ & $<.001$ & $123,465(66.4)$ & $971(66.4)$ & .98 \\
\hline Hyperlipidemia, n (\%) & $366,099(54.2)$ & $2795(51.0)$ & $<.001$ & $270,472(55.9)$ & $2034(51.2)$ & $<.001$ & $93,252(50.2)$ & $738(50.4)$ & .83 \\
\hline Charlson score, n (\%) & & & $<.001$ & & & $<.001$ & & & $<.001$ \\
\hline 0 & $184,731(27.4)$ & $0(0)$ & & $138,620(28.7)$ & $0(0)$ & & $45,529(24.5)$ & $0(0)$ & \\
\hline 1 & $266,716(39.5)$ & $1324(24.1)$ & & $197,843(40.9)$ & $956(24.1)$ & & $66,657(35.8)$ & $359(24.5)$ & \\
\hline 2 & $143,439(21.2)$ & $2288(41.7)$ & & $96,875(20.0)$ & $1696(42.7)$ & & $44,897(24.2)$ & $562(38.4)$ & \\
\hline 3 & $55,423(8.2)$ & $1208(22.0)$ & & $34,722(7.2)$ & $858(21.6)$ & & $19,975(10.7)$ & $346(23.6)$ & \\
\hline 4 & $17,230(2.6)$ & $469(8.6)$ & & $10,599(2.2)$ & $318(8.0)$ & & $6419(3.4)$ & $149(10.2)$ & \\
\hline$\geq 5$ & $7455(1.1)$ & $196(3.6)$ & & $4956(1.0)$ & $146(3.7)$ & & $2442(1.3)$ & $47(3.2)$ & \\
\hline Elective admission, n (\%) & $266,804(39.6)$ & $1890(34.5)$ & $<.001$ & $175,765(36.4)$ & $1175(29.6)$ & $<.001$ & $89,678(48.3)$ & $704(48.1)$ & .90 \\
\hline Weekend admission, $\mathrm{n}(\%)$ & $79,744(11.8)$ & $732(13.4)$ & $<.001$ & $60,235(12.5)$ & $578(14.5)$ & $<.001$ & $18,497(10.0)$ & $148(10.1)$ & .83 \\
\hline Primary payer, n (\%) & & & $<.001$ & & & $<.001$ & & & $<.001$ \\
\hline Medicare & $352,945(52.4)$ & $3569(65.2)$ & & $247,668(51.3)$ & $2589(65.2)$ & & $102,678(55.3)$ & $951(65.1)$ & \\
\hline Medicaid & $31,602(4.7)$ & $206(3.8)$ & & 22,981 (4.8) & $153(3.8)$ & & $8341(4.5)$ & $50(3.4)$ & \\
\hline Private & $248,432(36.8)$ & $1547(28.2)$ & & $182,058(37.7)$ & $1110(28.0)$ & & 64,243 (34.6) & $422(28.9)$ & \\
\hline Self-pay & $22,325(3.3)$ & $59(1.1)$ & & $16,884(3.5)$ & $42(1.1)$ & & $5198(2.8)$ & $17(1.2)$ & \\
\hline Other & $16,600(2.5)$ & $89(1.6)$ & & $11,860(2.5)$ & $70(1.8)$ & & $4560(2.5)$ & $18(1.2)$ & \\
\hline
\end{tabular}


TABLE 2. In-hospital mortality

\begin{tabular}{|c|c|c|}
\hline \multirow[b]{2}{*}{ Procedure } & \multicolumn{2}{|c|}{$\begin{array}{l}\text { OR for in-hospital mortality: } \\
\text { patients with RA compared } \\
\text { with control subjects }\end{array}$} \\
\hline & $\begin{array}{c}\text { Unadjusted OR } \\
(95 \% \text { CI })\end{array}$ & $\begin{array}{c}\text { Adjusted } * \text { OR } \\
(95 \% \text { CI })\end{array}$ \\
\hline Any revascularization & $0.87(0.69-1.09)$ & $0.51(0.40-0.65)$ \\
\hline CABG only & $0.89(0.62-1.26)$ & $0.69(0.48-0.99)$ \\
\hline PCI only & $0.78(0.57-1.07)$ & $0.39(0.29-0.54)$ \\
\hline PCI only with stent & $0.79(0.56-1.11)$ & $0.40(0.28-0.56)$ \\
\hline PCI only without stent & $0.77(0.32-1.86)$ & $0.37(0.15-0.93)$ \\
\hline \multicolumn{3}{|c|}{$\begin{array}{l}O R \text {, Odds ratio; } R A \text {, rheumatoid arthritis; } C I \text {, confidence interval; } C A B G \text {, coronary } \\
\text { artery bypass grafting; } P C I \text {, Percutaneous coronary intervention. *Adjusted for age, } \\
\text { age squared, sex, race/ethnicity, quartile income, rural-urban residency, hypertension, } \\
\text { hyperlipidemia, Charlson comorbidity index, elective admission, weekend admission, } \\
\text { and primary payer. }\end{array}$} \\
\hline
\end{tabular}

For patients undergoing coronary artery revascularization, patients with RA were $23 \%$ more likely (adjusted OR, $1.23 ; 95 \% \mathrm{CI}, 1.15-1.32)$ than the control group to undergo PCI rather than CABG. As a subgroup analysis, we separately evaluated in-hospital mortality in patients who underwent PCI and in patients who underwent CABG. Patients with RA were $61 \%$ less likely to die while hospitalized compared with the control group after PCI (adjusted OR, 0.39; 95\% CI, 0.29-0.54). This improved mortality was seen irrespective of whether patients had coronary artery stents placed (Table 2). Similarly, patients with RA were $31 \%$ less likely to die while hospitalized after CABG (adjusted OR, 0.69; 95\% CI, 0.48-0.99; Table 2).

For patients undergoing PCI, the hospital length of stay was 0.32 days shorter ( $95 \%$ CI, $0.28-0.34$ days) for patients with RA compared with the control group after adjusting for the same confounders (Table 3), with a median savings in total hospital charges of \$3391 (95\% CI, \$2638-\$4145; Table 4). For patients undergoing PCI, improvements were also seen irrespective of whether patients had coronary artery stents placed (Tables 3 and 4). Similarly, for patients undergoing $\mathrm{CABG}$, the length of stay was 1.36 days shorter (95\% CI, 0.72-1.12 days) for patients with RA, with a median savings in total hospital charges of $\$ 12,535$ (95\% CI, \$10,323-\$14,010).

\section{DISCUSSION}

Because RA is a risk factor for the development of coronary artery disease, because myocardial infarctions are the leading cause of mortality in patients with RA, and because patients with RA have more microvascular disease, we anticipated that patients with RA who underwent coronary revascularization procedures would have higher in-hospital mortality compared with that seen among patients without these underlying disorders. Paradoxically, we found the opposite. Among patients who underwent coronary artery revascularization, patients with RA were $49 \%$ less likely
TABLE 3. Length of stay

\begin{tabular}{|c|c|c|}
\hline \multirow[b]{2}{*}{ Procedure } & \multicolumn{2}{|c|}{$\begin{array}{l}\text { Change in length of stay }(d) \text { : } \\
\text { patients with RA compared } \\
\text { with control subjects }\end{array}$} \\
\hline & $\begin{array}{c}\text { Unadjusted median } \\
\qquad(95 \% \mathbf{C I})\end{array}$ & $\begin{array}{l}\text { Adjusted median* } \\
\qquad(95 \% \text { CI })\end{array}$ \\
\hline Any revascularization & $0.24(0.15$ to 0.30$)$ & $-0.57(-0.54$ to -0.63$)$ \\
\hline CABG only & $-0.48(-0.32$ to -0.72$)$ & $-1.36(-1.12$ to -0.72$)$ \\
\hline PCI only & $0.30(0.24$ to 0.36$)$ & $-0.32(-0.28$ to -0.34$)$ \\
\hline PCI only with stent & $0.32(0.26$ to 0.36$)$ & $-0.30(-0.26$ to -0.32$)$ \\
\hline PCI only without stent & $0.26(0.04$ to 0.52$)$ & $-0.38(-0.22$ to -0.52$)$ \\
\hline \multicolumn{3}{|c|}{$\begin{array}{l}R A \text {, Rheumatoid arthritis; } C I \text {, confidence interval; } C A B G \text {, coronary artery bypass graft- } \\
\text { ing; } P C I \text {, Percutaneous coronary intervention. *Adjusted for age, age squared, sex, } \\
\text { race/ethnicity, quartile income, rural-urban residency, hypertension, hyperlipidemia, } \\
\text { Charlson comorbidity index, elective admission, weekend admission, and primary } \\
\text { payer. }\end{array}$} \\
\hline
\end{tabular}

to die while hospitalized compared with patients without these conditions after adjusting for confounders. For patients with RA, this improvement was also seen in patients undergoing either PCI or CABG. Consistent with the primary observation, patients with RA had improved outcomes beyond in-hospital mortality as well. Compared with the control group, patients with RA undergoing either PCI or CABG had shorter lengths of stay and reduced total hospital charges after adjusting for confounders.

RA is now considered an independent risk factor for coronary artery disease, ${ }^{14}$ and chronic systemic inflammation is now understood to play a pivotal role in the development of accelerated atherosclerosis in patients with RA. ${ }^{15}$ Thus it is difficult to explain why a risk factor for the development of atherosclerosis would be associated with improved in-hospital mortality after coronary artery revascularization. These results cannot be explained by the age of these patients or their comorbid conditions because we adjusted for these confounders in our analysis. Moreover, the protective effect of RA remained when we included or excluded arthritis as a comorbid condition in calculating the Charlson or Elixhauser comorbidity indexes.

There is precedence for the paradoxic observation that a risk factor can be associated with improved mortality. Although hyperlipidemia is a risk factor for atherosclerosis, for example, it has also been found to be associated with improved in-hospital mortality. ${ }^{16}$ Therefore it is tempting to speculate that in patients with RA, there might be some difference in their atherosclerotic lesions, in their physiologic response to atherosclerotic lesions, or in their ability to heal after coronary artery revascularization procedures. Such differences might then lead to improvement in their clinical outcome after coronary artery revascularization. It is also interesting to note that prior studies demonstrated that statin pretreatment in patients undergoing coronary artery revascularization was associated with decreased risk of periprocedural myocardial infarction and long-term mortality. ${ }^{17,18}$ Moreover, C-reactive protein levels were reduced 
TABLE 4. Total hospital charges

\begin{tabular}{|c|c|c|}
\hline \multirow[b]{2}{*}{ Procedure } & \multicolumn{2}{|c|}{$\begin{array}{c}\text { Differences in total hospital charges (US\$): } \\
\text { patients with RA compared } \\
\text { with control subjects } \\
\end{array}$} \\
\hline & $\begin{array}{l}\text { Unadjusted median } \\
\qquad(95 \% \mathrm{CI})\end{array}$ & $\begin{array}{l}\text { Adjusted median* } \\
(95 \% \text { CI })\end{array}$ \\
\hline Any revascul & $-900(0$ & $-6300(-5$ \\
\hline CABG only & $\begin{array}{r}-8100(-5900 \text { to } \\
-10,300)\end{array}$ & $\begin{array}{c}-12,500(-10,300 \text { to } \\
-14,000)\end{array}$ \\
\hline PCI only & 1100 (400 to 1900$)$ & $-3400(-2600$ to -4100$)$ \\
\hline PCI only with stent & 1000 (300 to 1600$)$ & $-2600(-1900$ to -3200$)$ \\
\hline $\begin{array}{l}\text { PCI only without } \\
\text { stent }\end{array}$ & $-1400(-4200$ to 1900$)$ & $-4600(-4200$ to -9100$)$ \\
\hline \multicolumn{3}{|c|}{$\begin{array}{l}R A \text {, Rheumatoid arthritis; } C I \text {, confidence interval; } C A B G \text {, coronary artery bypass graft- } \\
\text { ing; } P C I \text {, Percutaneous coronary intervention. *Adjusted for age, age squared, sex, } \\
\text { race/ethnicity, quartile income, rural-urban residency, hypertension, hyperlipidemia, } \\
\text { Charlson comorbidity index, elective admission, weekend admission, and primary } \\
\text { payer. }\end{array}$} \\
\hline
\end{tabular}

with statin therapy, ${ }^{19}$ suggesting that some of the beneficial effects of statins might be mediated through control of inflammation. Disease-modifying agents for RA, such as methotrexate and tumor necrosis factor $\alpha$ inhibitors, also decrease C-reactive protein levels and more recently have been observed to decrease the risk for cardiovascular disease in these patients. ${ }^{19-21}$ It is tempting to speculate that patients with RA receive more aggressive treatment for inflammation than patients without these disorders and that this treatment to reduce inflammation might lead to the improved outcome compared with that seen in control subjects when they undergo coronary artery revascularization.

Inflammation in cardiac surgical patients is regulated by complex humoral and cellular interactions, including activation, generation, or enhanced expression of thrombin, complement, cytokines, neutrophils, adhesion molecules, mast cells, and other inflammatory mediators. ${ }^{22,23}$ Both proinflammatory and anti-inflammatory cytokines are produced during cardiopulmonary bypass. Multiple mediations and leukocyte depletion filters have been tried to attenuate the effects of these inflammatory cytokines. Although results have been variable, one study suggests that reducing CABG-influenced inflammation might reduce myocardial reperfusion injuries. ${ }^{24}$ Thus it is possible that the immunosuppression used in patients with RA might decrease postoperative complications in these patients, although there is no evidence to substantiate this hypothesis. Moreover, other mechanisms are involved because there are similar improvements in patients undergoing PCI.

Our results appear to differ from those of Van Doornum and colleagues, ${ }^{25}$ who reported that patients with RA had a higher 30-day mortality rate after their first myocardial infarction. This difference in mortality is likely explained by differences in the design of these studies. Using administrative databases from Australia, they studied a different population of patients, those who were hospitalized for their first myocardial infarction irrespective of whether they underwent coronary artery revascularization, whereas we analyzed all patients undergoing coronary artery revascularization irrespective of whether they had a myocardial infarction. Their end point was 30-day mortality, although they indicated that the majority of deaths occurred while patients were hospitalized. Both studies were observational, and therefore differences could potentially be explained by different patterns of practice for the selection of revascularization compared with medical therapy or even different patterns of treatment for RA. Indeed, in their population of patients, the adjusted OR to undergo PCI for patients with RA compared with that for patients without RA was 0.5 (95\% CI, 0.3-0.8), whereas in our population the adjusted OR to undergo PCI for patients with RA compared with that seen in the control group was 1.23 (95\% CI, 1.15-1.32).

There are some important limitations to our study. Because NIS is an administrative database, there will be inaccuracies in the diagnosis and coding of RA, as well as other comorbid conditions. Because there is no reason to suspect a systematic bias with coding or miscoding these disorders, these inaccuracies should therefore bias the results toward the null hypothesis. More importantly, this is an observational study from an administrative database and not a randomized trial, and therefore there is the possibility that unmeasured factors could influence the outcome. We cannot, for instance, adjust for use of medications, the extent of coronary artery disease, and ventricular function. Thus even though the data are suggestive, we cannot conclude that RA would have a protective effect on in-hospital mortality if patients were randomized. Indeed, physicians selected patients for PCI and CABG based on their opinion that these procedures would provide the best outcome for their patients. Because it is unlikely that we will ever have a randomized clinical trial to address the hypothesis of this study, it is reassuring to note that the current use of coronary artery revascularization for patients with RA in the United States appears beneficial. These results further suggest that there should not be undo concern about considering coronary artery revascularization in patients with these underlying disorders.

Despite these limitations, the finding that patients with RA undergoing coronary revascularization procedures have decreased in-hospital mortality compared with that seen in control subjects is, although surprising, provocative and should engender further investigation. Further studies are needed to confirm the dissociation in a risk factor for the development of a disease from its association with improved clinical outcomes, in this case patients with RA undergoing coronary artery revascularization. Such studies might not only help us better understand the pathogenesis of such disorders but also provide additional clues for successful therapy. 


\section{References}

1. Shoenfeld Y, Gerli R, Doria A, Matsuura E, Cerinic MM, Ronda N, et al. Accelerated atherosclerosis in autoimmune rheumatic diseases. Circulation. 2005;112: 3337-47.

2. Van Doornum S, McColl G, Wicks IP. Accelerated atherosclerosis: an extraarticular feature of rheumatoid arthritis? Arthritis Rheum. 2002;46:862-73.

3. Kaplan MJ, McCune WJ. New evidence for vascular disease in patients with early rheumatoid arthritis. Lancet. 2003;361:1068-9.

4. del Rincon I, Freeman GL, Haas RW, O'Leary DH, Escalante A. Relative contribution of cardiovascular risk factors and rheumatoid arthritis clinical manifestations to atherosclerosis. Arthritis Rheum. 2005;52:3413-23.

5. Roman MJ, Shanker BA, Davis A, Lockshin MD, Sammaritano L, Simantov R, et al. Prevalence and correlates of accelerated atherosclerosis in systemic lupus erythematosus. N Engl J Med. 2003;349:2399-406.

6. Raza K, Banks M, Kitas GD. Reversing myocardial microvascular disease in a patient with rheumatoid arthritis. J Rheumatol. 2005;32:754-6.

7. Sattar N, McCarey DW, Capell H, McInnes IB. Explaining how "high-grade", systemic inflammation accelerates vascular risk in rheumatoid arthritis. Circulation. 2003;108:2957-63.

8. MacLean CH, Louie R, Leake B, McCaffrey DF, Paulus HE, Brook RH, et al. Quality of care for patients with rheumatoid arthritis. JAMA. 2000; 284:984-92.

9. Moscucci M, Kline-Rogers E, Share D, O’Donnell M, Maxwell-Eward A, Meengs WL, et al. Simple bedside additive tool for prediction of in-hospital mortality after percutaneous coronary interventions. Circulation. 2001;104: 263-8.

10. O'Connor GT, Malenka DJ, Quinton H, Robb JF, Kellett MA Jr, Shubrooks S, et al. Multivariate prediction of in-hospital mortality after percutaneous coronary interventions in 1994-1996. Northern New England Cardiovascular Disease Study Group. J Am Coll Cardiol. 1999;34:681-91.

11. Wu C, Hannan EL, Walford G, Ambrose JA, Holmes DR Jr, King SB 3rd, et al. A risk score to predict in-hospital mortality for percutaneous coronary interventions. J Am Coll Cardiol. 2006;47:654-60.

12. Deyo RA, Cherkin DC, Ciol MA. Adapting a clinical comorbidity index for use with ICD-9-CM administrative databases. J Clin Epidemiol. 1992;45:613-9.

13. Elixhauser A, Steiner C, Harris DR, Coffey RM. Comorbidity measures for use with administrative data. Med Care. 1998;36:8-27.

14. Quyyumi AA. Inflamed joints and stiff arteries: is rheumatoid arthritis a cardiovascular risk factor? Circulation. 2006;114:1137-9.
15. Gonzalez-Gay MA, Gonzalez-Juanatey C, Lopez-Diaz MJ, Piñeiro A, GarciaPorrua C, Miranda-Filloy JA, et al. HLA-DRB1 and persistent chronic inflammation contribute to cardiovascular events and cardiovascular mortality in patients with rheumatoid arthritis. Arthritis Rheum. 2007;57:125-32.

16. Lee KL, Woodlief LH, Topol EJ, Weaver WD, Betriu A, Col J, et al. Predictors of 30-day mortality in the era of reperfusion for acute myocardial infarction. Circulation. 1995;91:1659-68.

17. Chan AW, Bhatt DL, Chew DP, Reginelli J, Schneider JP, Topol EJ, et al. Relation of inflammation and benefit of statins after percutaneous coronary interventions. Circulation. 2003;107:1750-6.

18. Collard CD, Body SC, Shernan SK, Wang S, Mangano DT, Multicenter Study of Peroperative Ischemia (MCSPI) Research Group, Inc; Ischemia Research and Education Foundation (IREF) Investigators. Perioperative statin therapy is associated with reduced cardiovascular mortality after coronary artery bypass surgery. J Thorac Cardiovasc Surg. 2006;132:392-400.

19. Naranjo A, Sokka T, Descalzo MA, Calvo-Alén J, Hørslev-Petersen K, Luukkainen RK, et al. Cardiovascular disease in patients with rheumatoid arthritis: results from the QUEST-RA study. Arthritis Res Ther. 2008;10:R30.

20. Carmona L, Descalzo MA, Perez-Pampin E, Ruiz-Montesinos D, Erra A, Cobo T, et al. All-cause and cause-specific mortality in rheumatoid arthritis are not greater than expected when treated with tumour necrosis factor antagonists. Ann Rheum Dis. 2007;66:880-5.

21. Jacobsson LT, Turesson C, Gülfe A, Kapetanovic MC, Petersson IF, Saxne T, et al. Treatment with tumor necrosis factor blockers is associated with a lower incidence of first cardiovascular events in patients with rheumatoid arthritis. J Rheumatol. 2005;32:1213-8.

22. Ilmakunnas M, Pesonen EJ, Ahonen J, Rämö J, Siitonen S, Repo H. Activation of neutrophils and monocytes by a leukocyte-depleting filter used throughout cardiopulmonary bypass. J Thorac Cardiovasc Surg. 2005;130:952-3.

23. Börgermann J, Friedrich I, Flohé S, Spillner J, Majetschak M, Kuss O, et al. Tumor necrosis factor-alpha production in whole blood after cardiopulmonary bypass: downregulation caused by circulating cytokine-inhibitory activities. J Thorac Cardiovasc Surg. 2002;124:608-17.

24. Sawa Y, Shimazaki Y, Kadoba K, Masai T, Fukuda H, Ohata T, et al. Attenuation of cardiopulmonary bypass-derived inflammatory reactions reduces myocardial reperfusion injury in cardiac operations. J Thorac Cardiovasc Surg. 1996;111:29-35.

25. Van Doornum S, Brand C, King B, Sundararajan V. Increased case fatality rates following a first myocardial event in patients with rheumatoid arthritis. Arthritis Rheum. 2006;54:2061-8. 